\title{
O IMAGINÁRIO DO MEDIEVAL FANTÁSTICO: o papel da direção de arte na construção da identidade visual de produções audiovisuais contemporâneas
}

\author{
Lucas Pessoa Pereira \\ Universidade Federal de Pelotas \\ lucaspergrafico@gmail.com \\ Ana Paula Cruz Penkala Dias \\ Universidade Federal de Pelotas \\ penkala@gmail.com \\ [Lúcia Bergamaschi Costa Weymar \\ Universidade Federal de Pelotas \\ luciaweymar@gmail.com]
}

\begin{abstract}
Resumo: O presente artigo apresenta de maneira introdutória uma pesquisa maior que trata do papel da direção de arte na construção da identidade visual de produções audiovisuais contemporâneas. A investigação se utiliza dos conceitos de imaginário e imageria para entender como essas práticas criativas atualizam, no período contemporâneo, o sentido de época da Idade Média. Neste texto, traz-se parte do material empírico a ser analisado, a saber, uma amostragem de tipografias produzidas entre os séculos VIII e XVI. Delimita-se aqui, também, as produções audiovisuais a serem analisadas, sendo elas uma franquia de filmes longa-metragem ( $O$ Senhor dos Anéis), uma série televisiva (Game of Thrones) e uma franquia de jogos eletrônicos (Warcraft). Os resultados atuais se limitam a catalogar, de modo inicial, os estilos de época do imaginário medieval.
\end{abstract}

Palavras-chave: imaginário, audiovisual, direção de arte, identidade visual, medieval fantástico

Abstract: This paper presents, in an introductory way, a larger research that addresses the role of production design in the construction of the branding of contemporary audiovisual productions. The research uses the concepts of imaginary and imagery to understand how these creative practices update, in the contemporary period, the sense of time of the Middle Ages. This text brings a part of the empirical material to be analyzed, namely, a sampling of typefaces produced between the eighth and sixteenth centuries. It is also delimited here audiovisual productions to be analyzed, such as a franchise of feature films (The Lord of the Rings), a 
television series (Game of Thrones) and a videogame franchise (Warcraft). The current results are limited on cataloging, in an initial way, the age styles of the medieval imaginary.

Keywords: imaginary, audiovisual, production design, branding, high fantasy

\section{INTRODUÇÃO}

Este artigo faz parte de uma pesquisa maior que propõe uma abordagem sobre a identidade visual, dentro do projeto da direção de arte, na construção de imaginários de época nas produções audiovisuais contemporâneas, especificamente as de época medieval que tem o fantástico como elemento narrativo principal. O presente texto tem como escopo apresentar a pesquisa e delimitar os objetos empíricos da investigação.

A identidade visual, enquanto saber e prática do design, é utilizada nas narrativas audiovisuais enquanto projeto que costura um conjunto de elementos formais que representa e dá a conhecer, visualmente, um filme, uma série, um personagem ou até um gênero narrativo. Enquanto no design gráfico essa prática é aplicada com o intuito de representar - em um contexto e por meio de vários elementos - um nome, ideia, produto ou serviço, geralmente relacionando-se a marcas e logotipos, no audiovisual esse conceito se amplia, abarcando aspectos e elementos específicos das narrativas audiovisuais. Em filmes, séries, videoclipes, videogames e outros produtos, esses elementos e aspectos se referem, então, aos traços formais identitários da obra que incluem desde iluminação e paleta de cores até cenários e figurinos, passando também por elementos como o título e até material gráfico inserido no contexto da narrativa. O papel da direção de arte no audiovisual é, além de traduzir visualmente a ideia geral encerrada no roteiro e no projeto do diretor, também o de construir a identidade visual dessa obra. Nesse sentido, a direção de arte se define, resumidamente, como a realização visual da narrativa da produção. Segundo Georgina Shorter, a direção de arte "[...] abrange a concepção, o design, a criação e o arranjo de todos os elementos visuais da narrativa fílmica e assegura que todas as concepções corram consistentemente e coerentemente pela história" (2012, p. 7-8, tradução minha) $)^{1}$.

As produções audiovisuais usam a direção de arte (e a direção de fotografia), para construir a narrativa visual daquilo que almejam representar. Dentro dessa tecitura narrativa, a identidade visual é, como resume Shorter (2012) sobre o papel da direção de arte, o que funciona como um fio condutor no projeto. Esta pesquisa está delimitada sobre aspectos, elementos e princípios da direção de arte onde esteja aplicado o conceito de identidade visual.

Na contemporaneidade, é possível observar recorrências de uma temática específica representada nas produções audiovisuais: o imaginário medieval dentro de narrativas do gênero fantástico. Esse imaginário é constituído por temáticas e cultura visual que marcam e caracterizam o período através do uso de elementos que dão a

\footnotetext{
${ }^{1}$ It encompasses the concept, design, creation and arrangement of all visual elements in a screen narrative and ensures that all conceptual ideas run consistently and coherently throughout the story.
} 
reconhecer aquele tempo ou sugerem uma "atmosfera" relacionada a esses temas e cultura visual, dentre os quais podemos falar de uma imageria ${ }^{2}$ daquela época. O que é compreendo aqui como cultura visual é o conjunto de práticas, hábitos e produtos culturais relacionados ao visual e às imagens, sendo esse conjunto algo próprio de uma sociedade ou contexto histórico e essas imagens ou produtos visuais sendo atravessados por essas práticas e hábitos. $O$ conceito será discutido aprofundadamente no decorrer da pesquisa maior. O universo ficcional fantástico se define como o que tem a magia, a mitologia ou a fantasia como argumento central da história, ou então que tem esses elementos como pano de fundo, ou ainda complementares a ela. A união dessas ideias - o medieval perpassado pelo fantástico na produção audiovisual contemporânea, que é aqui definida por séries televisivas, filmes e jogos eletrônicos, é o que delimita o universo desta pesquisa.

O problema de pesquisa surge desse contexto e apresenta-se na forma de uma questão: como a direção de arte, utilizando os princípios da identidade visual e a cultura visual, atualiza o imaginário medieval em produtos audiovisuais contemporâneos com universos ficcionais fantásticos?

Quanto aos objetivos da pesquisa, define-se como geral o de compreender como a direção de arte, através dos princípios da identidade visual, atualiza o imaginário medieval nas narrativas fantásticas em produções audiovisuais contemporâneas. Os objetivos específicos são: (a) investigar as relações entre o imaginário medieval e os universos fantásticos da fiç̧ão, mapeando esses elementos e princípios em produções audiovisuais contemporâneas; (b) compreender como a direção de arte lança mão da cultura visual e, através de elementos e princípios da identidade visual, atualiza o imaginário medieval, como o representa, reforça e/ou o modifica em narrativas do gênero fantástico; e (c) refletir e discutir sobre como as representações visuais, a cultura visual e a maneira como design e audiovisual atualizam e produzem sentidos de época através da identidade visual.

\section{DESENVOLVIMENTO}

Enquanto práticas de produção cultural, tanto o design quanto o audiovisual que engloba desde o cinema até séries televisivas e jogos eletrônicos - reproduzem, atualizam e criam imaginários e uma cultura visual. Ajudam a construir e ao mesmo tempo representam a cultura visual de uma sociedade e de uma época. A recorrência de estilos, estéticas e imaginários de outras épocas nas produções culturais contemporâneas e a forma com que as práticas do design se apropriam desses estilos, estéticas e imaginários nos revelam sobre a época em que vivemos. Nos últimos vinte anos, a produção audiovisual vem reiteradamente fazendo uma apropriação da cultura visual do período medieval, através de séries, filmes, videogames e outros produtos que tematizam o período, sobretudo a partir de narrativas fantásticas. O tema não é novo, especialmente no cinema, porém a forma com que o design - seus saberes, princípios e práticas - o representa é. Nunca a direção de arte de narrativas fantásticas buscou tanta precisão na representação de estilos, estéticas e do imaginário medieval - a despeito dos altos custos de produção - em narrativas que, pelo contrário,

\footnotetext{
2 "[...] imageria é o conjunto de imagens relativas a uma dada coisa. [...] Essas imagens formam um conjunto a partir de um elemento de coesão, que lhes é externo. [...] É um conjunto de imagens formadas a partir de um consciente que as agrupa por sua natureza figurativa, por semelhanças ou por importância relativa à dada coisa." (PENKALA, 2011, p. 18-19). O conceito será melhor abordado posteriormente.
} 
permitem a licença poética e um menor compromisso histórico com a cultura visual do período. Isto posto, serão consideradas na pesquisa, portanto, as representações visuais, a cultura visual e a maneira como o design e o audiovisual atualizam sentidos de época através da identidade visual.

Ao revelar um gosto de época (JAMESON, 1996), a recorrência na representação de estilos, estéticas e um imaginário do medieval nas produções contemporâneas permite que percebamos, também, de que forma o mercado absorve essas narrativas. No sentido de compreender o trânsito que essas recorrências tem entre as produções audiovisuais contemporâneas, três produtos servem, aqui, de objeto empírico para a pesquisa. Narrativas que se realizam em três suportes e formatos diferentes, esses produtos são, tanto no mercado audiovisual quanto em cada um de seus tipos de produção específicos, sucesso de público e de crítica: a franquia de jogos eletrônicos Warcraft, distribuído pela empresa americana de videogames Blizzard Entertainment e que tem como temática um universo fictício onde as referências visuais e culturais do medieval fantástico são claramente demarcadas, além de ser atualmente focado na modalidade de jogo MMORPG (massive multiplayer online role-playing game ${ }^{3}$ ) com a série World Of Warcraft, que permite a criação de personagens nesse mundo virtual por milhares de jogadores simultaneamente; a franquia de filmes $O$ Senhor dos Anéis, iniciada pelo filme $O$ Senhor dos Anéis: A Sociedade do Anel (The Lord of the Rings: The Fellowship of The Ring, Peter Jackson, 2001) e baseada na obra de mesmo nome de autoria de J. R. R. Tolkien, escritor e filólogo inglês que escreveu o livro em forma de trilogia entre os anos de 1937 e 1949, época da Segunda Guerra Mundial que serve como referência, mesmo que talvez de maneira indireta, para a construção de imaginário que o autor realiza; e a série televisiva produzida pelo canal HBO Guerra dos Tronos (Game of Thrones, produzida por David Benioff e D. B. Weiss, 2011), baseada na obra de fantasia épica As Crônicas de Gelo e Fogo (A Song Of Ice And Fire) do autor americano George R. R. Martin, que lançou o primeiro livro da série em 1996. Considerando esse escopo, considera-se relevante a compreensão sobre o processo de criação desses universos fantásticos com referências do medieval como forma de entender também a cultura visual contemporânea.
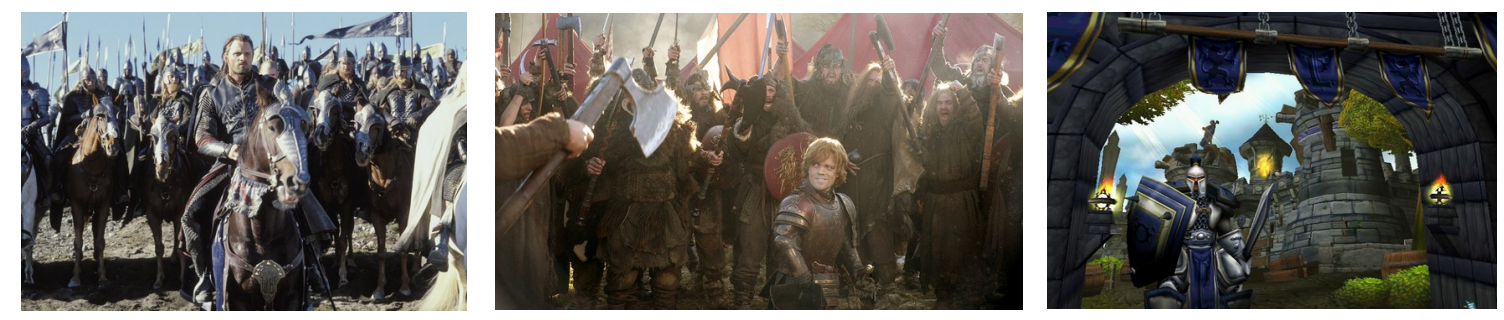

Figura 1 - stills das produções audiovisuais selecionadas (na imagem à esquerda: $O$ Senhor dos Anéis; na imagem central: Game Of Thrones; na imagem à direita: Warcraft).

Fonte: http://images.google.com/

O imaginário, conceito que atravessa a pesquisa proposta, é entendido aqui a partir de Michel Maffesoli (2001) que, num primeiro momento, indica o contraponto

\footnotetext{
3 "Jogo online de interpretação de personagens e em massa para múltiplos jogadores", tradução livre.
} 
existente entre o conceito de imaginário para várias vertentes do pensamento contemporâneo. Em algumas abordagens, segundo o autor, o imaginário seria o oposto do real ou do verdadeiro, sendo esse real referente à realidade consistente, seja ela econômica, política ou social - ou seja, aquilo que é palpável, tangível, observável ou administrável no plano do concreto, o mundo material. Essa noção de oposição entre o imaginário e o real é apontada pelo autor como consolidada há muito tempo. Nas décadas de 1930 e 1940, Gaston Bachelard e Gilbert Durand colocam um segundo sentido sobre o termo. Ainda segundo Maffesoli, tratam o real como, na verdade, acionado e influenciado pelo imaginário. O conceito de imaginário usado neste projeto é aquele que este autor explora ao falar sobre a relação entre imaginário e cultura:

\begin{abstract}
A cultura, no sentido antropológico dessa palavra, contém uma parte de imaginário. Mas ela não se reduz ao imaginário. É mais ampla. Da mesma forma, agora pensando em termos filosóficos, o imaginário não se reduz à cultura. Tem certa autonomia. Mas, claro, no imaginário entram partes de cultura. A cultura é um conjunto de elementos e de fenômenos passíveis de descrição. O imaginário tem, além disso, algo de imponderável. É o estado de espírito que caracteriza um povo. Não se trata de algo simplesmente racional, sociológico ou psicológico, pois carrega também algo de imponderável, um certo mistério da criação ou da transfiguração. (MAFFESOLI, 2001, p. 75, grifos meus)
\end{abstract}

A cultura, para Maffesoli, é algo passível de ser identificado de forma precisa, enquanto que o imaginário teria um caráter ambiental e atmosférico, "aquilo que Walter Benjamin chama de aura" (MAFFESOLI, 2001, p. 75), sendo então uma construção mental coletiva perceptível, "mas não quantificável” (idem). Essa natureza coletiva do imaginário é enfatizada pelo autor, que aponta que o imaginário não pode ser individual, exatamente por se tratar dessa atmosfera, desse cimento social, desse estado de espírito de um grupo, a aura que atravessa e alimenta a cultura desse grupo. Maffesoli estreita o entendimento sobre o imaginário quando fala sobre a relação intrínseca que este tem com a imagem:

\footnotetext{
Não é a imagem que produz o imaginário, mas o contrário. A existência de um imaginário determina a existência de conjuntos de imagens. A imagem não é o suporte, mas o resultado. Refiro-me a todo tipo de imagens: cinematográficas, pictóricas, esculturais, tecnológicas e por aí afora. Há um imaginário parisiense que gera uma forma particular de pensar a arquitetura, os jardins públicos, a decoração das casas, a arrumação dos restaurantes, etc. O imaginário de Paris faz Paris ser o que é. Isso é uma construção histórica, mas também o resultado de uma atmosfera e, por isso mesmo, uma aura que continua a produzir novas imagens. (MAFFESOLI, 2001, p. 76)
}

De forma complementar a essa ideia, para o autor, o imaginário toma como suporte de dispersão a comunicação, principalmente no que se refere às tecnologias e técnicas respectivas. Tomando isso como base, considera-se aqui que, portanto, a construção de um imaginário depende também das imagens, estabelecendo-se, dessa forma, uma relação ambígua de retroalimentação entre imaginário e imagens: o imaginário cria imagens que criam o imaginário (ideia que vai, de certa forma, de encontro ao que é proposto por Maffesoli). Nesse ponto é pertinente pensarmos o 
conceito de imageria, que se define como um conjunto de imagens referentes a algo, agrupadas "por sua natureza figurativa, por semelhanças ou por importância relativa a dada coisa" (PENKALA, 2011, p. 19). A relação direta entre imageria e imaginário é estabelecida pela autora quando ela afirma que "a imageria é parte de um imaginário ao mesmo tempo em que é constituída por ele." (ibidem, p. 21).

Considerando o objeto desta pesquisa, é possível notar a recorrência de um imaginário medieval expresso em algumas narrativas contemporâneas. Essa recorrência é percebida pela representação (visual ou não) da realidade dessa época, movimentando sua imageria correspondente e referências ao contexto (histórico) do medievo e lançando à cultura visual contemporânea esse "medieval" reconstruído. Esse imaginário medieval aparece nas produções audiovisuais observadas tanto nas referências à organização social, política e cultural de época e ao espaço geográfico específico (a Europa ocidental, por exemplo), com seu sistema monárquico baseado na sucessão de poder através da herança de nome, a centralização do poder em um único indivíduo, as relações de títulos de nobreza e as respectivas imbricações familiares, a influência direta da religião no modo de governar, as noções de honra e lealdade ao monarca, etc; quanto na leitura de uma cultura visual que se entende como medieval, representada concretamente na arquitetura, nas artes e no vestuário, entre outros elementos visuais e constitutivos que podem ser depreendidos da imageria daquele período e contexto.

Nesse sentido, imaginário e imageria servem como base para o processo criativo nessas narrativas audiovisuais, atravessando o projeto de identidade visual de forma a torná-lo a um só tempo coerente com a narrativa, coeso com esse imaginário e com o contexto histórico ao qual se faz referência (direta ou indireta) e capaz de "costurar" o produto (série, filme, jogo eletrônico) a partir de elementos que conduzem o espectador dentro da narrativa, constroem sentido e operam de forma a garantir uma unidade e coerência visual ao projeto.

Isto posto, parte-se para algumas considerações acerca das práticas estudadas nesta proposta de investigação. A prática da criação de identidades visuais é aqui considerada como uma ferramenta projetual que, tanto no design quanto no cinema, na animação e na produção de jogos eletrônicos, é construída a partir da conceituação daquilo que quer ser representado formalmente através de símbolos, cores, tipografia, elementos gráficos de apoio e outros que identificam e delimitam, em termos visuais, como determinada produção será representada concretamente. Enquanto prática e saber, a identidade visual é, para o design, uma das principais atividades, especialmente em se tratando de sua natureza projetual. Como projeto, esse processo que é também de criação comumente assimila imaginários e contribui para sua construção nas práticas culturais, especialmente no que se refere à cultura visual. Tomando isso como base, destaca-se aqui a relevância de uma observação e análise sobre o papel da direção de arte e da identidade visual no que se refere a um imaginário de outra época apresentado no contemporâneo, a saber, o imaginário do medieval fantástico, que, acredita-se, revela um novo olhar para a época. Considerando o design enquanto prática e saber que lida com o imaginário, e a identidade visual enquanto projeto que (re)constrói imaginários, a tarefa do designer, nesse processo, é, como aponta Timothy Samara, a de que os outros possam entendê-las. O designer utiliza imagens, símbolos, 
tipos, cor e material - seja este físico como a impressão de uma página, ou algo intangível como pixels em uma tela de computador ou luz em um vídeo - para representar as ideias que devem ser transmitidas e organizá-las em uma mensagem unificada. [...] O designer gráfico assimila conceitos verbais e Ihes dá forma. Ele organiza a forma resultante em uma experiência tangível e navegável. (SAMARA, 2010, p. 6-7)

Essa conceituação abrangente é aplicada diretamente no processo de criação de identidades visuais, um dos pontos-chave para entendimento dessa produção de sentido na cultura, tomando como base a ideia de que o designer

é responsável pela vitalidade intelectual e emocional da mensagem que ele transmite ao público. Sua tarefa é elevar a experiência da mensagem além da banalidade da transmissão literal e do enganoso egoísmo consumista voltado apenas para o mero entretenimento ou para a autossatisfação [...]. (SAMARA, 2010, p. 7)

Um dos pontos específicos que se deve notar na produção visual que constrói imaginários, e que terá foco específico em etapa determinada da pesquisa, é o uso da tipografia. Conforme aponta Lupton, a relevância da tipografia se dá no sentido de que é importante "pensar com tipos (com ênfase para o com). A tipografia é uma ferramenta com a qual o conteúdo ganha forma, a linguagem ganha um corpo físico e as mensagens ganham um fluxo social." (2006, p. 8), ideia corroborada por Robert Bringhurst, que postula que "A tipografia é o ofício que dá forma visível e durável - e, portanto, existência independente - à linguagem humana." (2011, p 17). Nesse sentido, um dos focos do trabalho também será o de mapear e analisar tanto as tipografias que foram produzidas e fazem parte do período histórico abordado, quando as contemporâneas que traduzem visualmente esse sentido de época. Como amostragem inicial, traz-se aqui alguns exemplos de tipografias catalogadas na obra The Book of Ornamental Alphabets, Ancient and Mediæval, from the Eighth Century. 0 livro em questão elenca diversos exemplos de tipografias produzidas desde o século VIII até o século XVI.
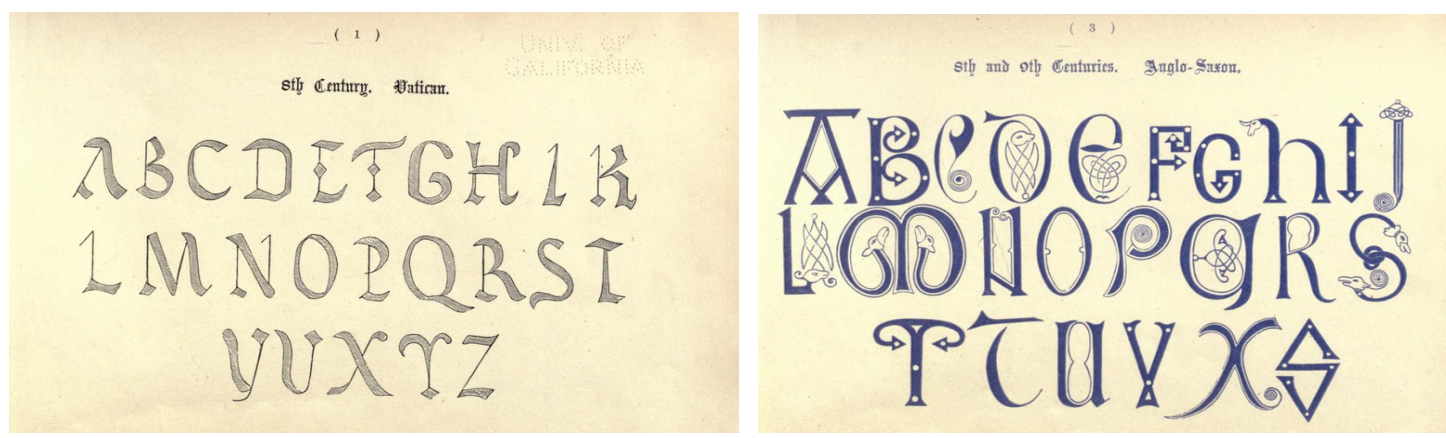

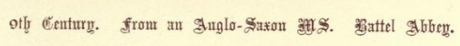
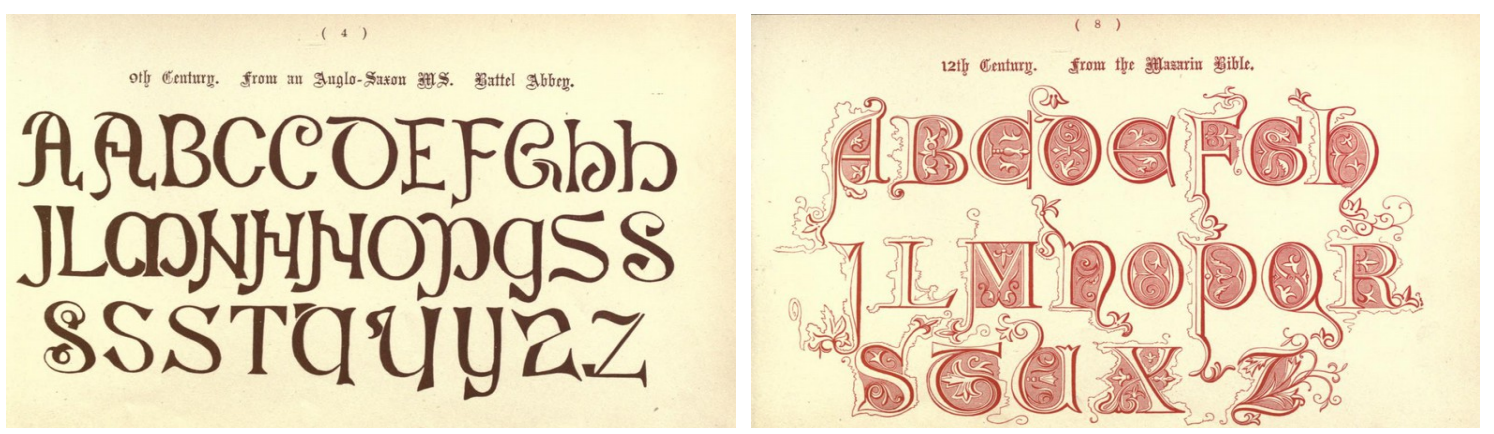
Figura 2 - exemplos da amostragem de tipografias medievais. Nas imagens superiores: alfabetos desenhados no século VIII; na imagem inferior à esquerda: alfabeto desenhado no século IX; na imagem inferior à direita: alfabeto desenhado no século XII.

Fonte: DELAMOTTE, 1914.

É possível observar através destes exemplos que, durante o decorrer dos séculos, os estilos gráficos dos alfabetos acabam por eventualmente destoar entre si, mesmo que não necessariamente de maneira brusca. A utilização, por exemplo, de símbolos ilustrativos, arabescos, ornamentos (geométricos e orgânicos), e outros apoios gráficos às letras, bem como os primeiros esboços de construção tipográfica gótica, ou então um estilo estético ligeiramente mais primitivo, ligado à cultural celta, gera um espectro estilístico que traduz visualmente o imaginário da época medieval, bem como estabelece uma imageria relacionada.

No que se refere à metodologia de pesquisa que será empregada na investigação maior, pretende-se trabalhar com a ideia de um percurso metodológico, que se propõe em adequar procedimentos da prática do design ao objeto empírico do audiovisual. Desta forma, a partir dos referenciais teóricos (especialmente aqueles que dão conta da cultura visual e do imaginário) e do atravessamento, neles, das abordagens projetuais do design, será feito um cruzamento do percurso sugerido em Penkala (2011), a partir de onde se compreende uma observação de elementos recorrentes no objeto empírico (os filmes, a série e o jogo eletrônico), na forma de suas narrativas (neste caso, visuais), com o referencial metodológico da Análise Fílmica (AUMONT e MARIE, 2009). Para tanto, será feito um mapeamento dos elementos identitários do universo visual medieval nessas produções e em outras (que possam servir de panorama) para a compreensão de como o imaginário desse período se atualiza na cultura visual contemporânea. O mapeamento em si apontará a construção da metodologia de análise, uma vez que, segundo os autores, "[...] o filme é o ponto de partida e deve ser o ponto de chegada da análise" (AUMONT e MARIE, 2009, p. 33), e não existe um método universal para esse tipo de análise, considerando-se que é a abordagem do filme (ou da obra audiovisual) quem vai apontar instrumentos, técnicas e percursos de observação. Observando-se as recorrências e elementos que referenciem, nesses produtos, o medieval enquanto imaginário e cultura visual, propõe-se uma reflexão e discussão sobre o processo de criação construído pelo design e dentro de suas práticas projetuais para a elaboração dessas identidades visuais medievais no contexto das narrativas fantásticas.

\section{CONCLUSÃO}

Em um primeiro momento de deparo empírico com o material a ser analisado para a investigação, é possível observar que existe uma riqueza de produção visual referente à época da Idade Média, sendo essa gama imagética essencial para a pesquisa, visto que é a partir dela que será possível um entendimento de onde surge e como se consolida o que aqui é defendido como sendo um imaginário medieval. Por conta de ainda se encontrar em um estágio inicial, a presente pesquisa traz, em termos de resultado, uma catalogação inicial da amostragem de tipografias que definem, em parte, um estilo de época baseado no imaginário medieval. 


\section{REFERÊNCIAS}

AUMONT, Jacques; MARIE, Michel. A análise do filme. Lisboa: Texto \& Gráfica, 2009.

BRINGHURST, Robert. Elementos do Estilo Tipográfico. São Paulo: Cosac Naify, 2011.

DELAMOTTE, Freeman Gage. The Book of Ornamental Alphabets. Londres: Crosby Lockwood And Son, 1914. Disponível em: <http://goo.gl/oyxAjK>

JAMESON, Fredric. Pós-modernismo: A lógica cultural do capitalismo tardio. São Paulo: Editora Ática, 1996.

LUPTON, Ellen. Pensar com tipos: guia para designers, escritores, editores e estudantes. São Paulo: Cosac Naify, 2006.

MAFFESOLI, Michel. O imaginário é uma realidade. Revista Famecos, Porto Alegre, no 15, agosto de 2001.

PENKALA, Ana Paula. 0 mal-estar na visualização e outras estéticas: da imageria do audiovisual pós-moderno. Tese (Doutorado em Comunicação e Informação) Programa de Pós-Graduação em Comunicação e Informação (Universidade Federal do Rio Grande do Sul), Porto Alegre/RS, 2011.

SAMARA, Timothy. Elementos do design: guia de estilo gráfico. Porto Alegre: Bookman, 2010.

SHORTER, Georgina. Designing for screen: Production Design and Art Direction explained. The Crowood Press: Marlborough, 2012. 